\title{
Peripheral haemodynamic effects of inhibition of prostaglandin synthesis in congestive heart failure and interactions with captopril
}

\author{
J N Townend, J Doran, C J Lote, M K Davies
}

University of Birmingham Departments of Cardiovascular Medicine and Physiology, Queen Elizabeth Hospital, Edgbaston,

Birmingham

J N Townend

J Doran

C J Lote

M K Davies

Correspondence to:

Dr J N Townend, University of Birmingham Departments of Cardiovascular Medicine and Physiology, Que Elizabeth Hospital Edgbaston, Birmingham B15 2TH.

Accepted for publication 20 December 1994

\begin{abstract}
Objectives-To investigate the role of prostaglandins in maintaining circulatory homoeostasis in chronic heart failure and the hypothesis that an increase in vasodilatory prostaglandin synthesis may contribute to the actions of angiotensin converting enzyme inhibitors in heart failure.
\end{abstract}

Design-Randomised, double blind, placebo controlled studies. Cardiac output and renal and limb blood flow were measured after oral indomethacin $50 \mathrm{mg}$ or placebo followed by "open" intravenous infusion of prostaglandin $E_{2}$ (study $A$ ). In a second study the same measurements were made after oral indomethacin $50 \mathrm{mg}$ or placebo was given $30 \mathrm{~min}$ before "open" captopril (study B).

Methods-Blood pressure was measured using a mercury sphygmomanometer. Cardiac output was determined by Doppler interrogation of blood flow in the ascending aorta and echocardiographic measurement of aortic root diameter. Renal blood flow was calculated from the effective renal plasma flow measured by $p$-aminohippurate clearance and the haematocrit, and glomerular filtration rate by endogenous creatinine clearance. Limb blood flow was measured by venous occlusion plethysmography using mercury in silastic strain gauges. The concentration of plasma prostaglandin $E_{2}$ was measured by radioimmunoassay.

Setting-University department of cardiovascular medicine.

Patients-12 patients with chronic stable heart failure before starting treatment with angiotensin converting enzyme inhibitors.

Results-Indomethacin resulted in adverse effects on cardiac output, systemic vascular resistance, renal blood flow, glomerular filtration, urinary sodium excretion, and calf vascular resistance. Changes were reversed with infusion of prostaglandin $E_{2}$. Pretreatment with indomethacin resulted in the attenuation of the acute increase in cardiac output and decrease in systemic vascular resistance that occurred with captopril. Similarly, an increase in renal blood flow with captopril was attenuated by indomethacin.

Conclusions-The acute adverse effects of indomethacin on central and peri- pheral haemodynamic and renal function suggest that prostaglandins have a significant role in the regulation of peripheral blood flow and renal function in patients with stable chronic heart failure. The attenuation by indomethacin of captopril induced improvements in haemodynamic function and renal blood flow is consistent with the hypothesis that captopril may act in part via an increase in prostaglandin synthesis.

(Br Heart f 1995;73:434-441)

Keywords: haemodynamic and renal effects of indomethacin; captopril; congestive heart failure; prostaglandins.

Prostaglandins are 21 carbon fatty acids synthesised from arachidonic acid by all body tissues including the kidney and vascular endothelium. Stimuli to prostaglandin production include ischaemia, catecholamines, angiotensin II, bradykinin, and vasopressin. ${ }^{12}$ Prostaglandins $E_{2}$ and $I_{2}$ are potent vasodilators and are thought to act locally to increase blood flow. ${ }^{2}$ Many of the factors known to stimulate prostaglandin synthesis are present in heart failure and circulating concentrations of metabolites of prostaglandins $\mathrm{E}_{2}$ and $\mathrm{I}_{2}$ are increased in some patients with heart failure. ${ }^{3}$ It has been suggested that vasodilatory prostaglandins have an important role in maintaining circulatory homoeostasis in heart failure when tissue perfusion is reduced. ${ }^{4}$ In parallel with the activation of nervous and humoral vasoconstrictor systems, increased prostaglandin synthesis may act as a "counter regulatory" mechanism to limit local vasoconstriction and maintain local blood flow. Uncontrolled studies have shown adverse renal and systemic haemodynamic effects after inhibition of prostaglandin synthesis in chronic heart failure. ${ }^{35}$

Angiotensin converting enzyme and kininase II are structurally identical so that angiotensin converting enzyme inhibitors not only inhibit the renin angiotensin system but also inhibit the degradation of kinins. Bradykinin is a potent vasodilator and also a stimulus to the synthesis of prostaglandins. ${ }^{6}$ This pivotal position of the angiotensin converting enzyme means that angiotensin converting enzyme inhibitors not only inhibit the vasoconstrictor renin angiotensin system but may also facilitate the production of vasodilators such as bradykinin and prostaglandin. 


\begin{tabular}{|c|c|c|c|c|c|c|}
\hline Patient no & $\begin{array}{l}\text { Age } \\
\text { (years) }\end{array}$ & Sex & Diagnosis & $\begin{array}{l}\text { Ejection } \\
\text { fraction } \\
(\%)\end{array}$ & $\begin{array}{l}\text { NYHA } \\
\text { class }\end{array}$ & $\begin{array}{l}\text { Frusemide } \\
\text { (mg/day) }\end{array}$ \\
\hline $\begin{array}{r}1 \\
2 \\
3 \\
4 \\
5 \\
6 \\
7 \\
8 \\
9 \\
9 \\
10 \\
11 \\
12\end{array}$ & $\begin{array}{l}48 \\
62 \\
64 \\
69 \\
54 \\
68 \\
42 \\
66 \\
67 \\
61 \\
58 \\
60\end{array}$ & $\begin{array}{l}F \\
F \\
M \\
M \\
M \\
M \\
M \\
F \\
M \\
M \\
M \\
M\end{array}$ & $\begin{array}{l}\text { CAD } \\
\text { CAD } \\
\text { CAD } \\
\text { CAD } \\
\text { DCM } \\
\text { CAD } \\
\text { DCM } \\
\text { CAD } \\
\text { CAD } \\
\text { CAD } \\
\text { CAD } \\
\text { CAD }\end{array}$ & $\begin{array}{l}17 \\
13 \\
17 \\
27 \\
32 \\
31 \\
30 \\
19 \\
20 \\
22 \\
27 \\
18\end{array}$ & $\begin{array}{l}\text { III } \\
\text { IV } \\
\text { III } \\
\text { III } \\
\text { III } \\
\text { III } \\
\text { III } \\
\text { IV } \\
\text { IV } \\
\text { III } \\
\text { III } \\
\text { IV }\end{array}$ & $\begin{array}{r}80 \\
80 \\
160 \\
80 \\
80 \\
80 \\
80 \\
120 \\
80 \\
80 \\
40 \\
160\end{array}$ \\
\hline mean $(\mathrm{SD})$ & $60(8)$ & & & $23(6)$ & & $93(35)$ \\
\hline
\end{tabular}

CAD, coronary artery disease; DCM, dilated cardiomyopathy; NYHA, New York Heart Association.

Despite reducing many stimuli to prostaglandin production treatment with captopril seems to increase rather than reduce the circulating concentration of vasodilatory prostaglandins in patients with heart failure. ${ }^{7}$ There is evidence that in patients with essential hypertension the hypotensive effects of captopril may be mediated in part by an increase in prostaglandin production ${ }^{89}$ and it is possible that some of the effects of captopril in heart failure may also be mediated by prostaglandins.

Prostaglandin synthesis can be inhibited by inhibitors of cyclo-oxygenase such as indomethacin. Because prostaglandins are not stored but are synthesised de novo their actions are inhibited by such agents. We have administered indomethacin to patients with heart failure in an attempt to determine the role of prostaglandins in the maintenance of renal and skeletal muscle blood flow in heart failure. Second, we have investigated the role of prostaglandins in mediating the acute haemodynamic effects of captopril in heart failure by comparing the effects of captopril with and without pretreatment with indomethacin.

\section{Patients and methods}

PATIENTS

Twelve patients (nine men) with chronic stable heart failure in New York Heart Association symptomatic class III or IV who had never received treatment with angiotensin converting enzyme inhibitors were studied. The mean (SD) age was 60 (8) years and the mean (SD) ejection fraction determined by radionuclide ventriculography was 23 (6)\%. All patients were receiving chronic diuretic medication, the dosage of which was maintained without change for at least 2 weeks before the studies. No patient was taking concurrent vasodilator medication. The table gives the causes of heart failure and other individual patient details. Each patient gave written consent and the study was approved by the ethics committee of the South Birmingham Health Authority.

\section{RENAL BLOOD FLOW}

Renal blood flow was determined by measurement of effective renal plasma flow using $p$ - aminohippurate clearance. ${ }^{10}$ Renal blood flow was calculated as effective renal plasma flow $\times 1$ /haematocrit. Renal vascular resistance was calculated as the ratio of mean blood pressure to renal blood flow and the results expressed in dyne.s.cm ${ }^{-5} \times 10^{3}$. The concentration of $p$-aminohippurate in plasma and urine was assayed in duplicate using a colorimetric assay.

\section{GLOMERULAR FILTRATION RATE}

Glomerular filtration rate was measured by endogenous creatinine clearance.

\section{LIMB PLETHYSMOGRAPHY}

Forearm and calf blood flow were measured by venous occlusion plethysmography using mercury in silastic strain gauges connected to a plethysmograph (Hokanson EC-4; DE Hokanson, WA, USA) the output of which was connected to a pen chart recorder (Oxford Instrument Company, UK). The venous cuff was connected to a rapid cuff inflator device (Hokanson E-20 rapid cuff inflator) filled from a compressor (Hokanson AG-101 cuff inflator source) allowing inflation of the cuff to a preset pressure $(50 \mathrm{~mm}$ $\mathrm{Hg}$ ) in less than $0.3 \mathrm{~s}$. Arterial occlusion to the hand or foot was provided by a cuff connected via a three way tap to a reservoir containing air at a pressure of $200 \mathrm{~mm} \mathrm{Hg}$. The limb bearing the apparatus was positioned above heart height before readings were taken. Limb blood flow was derived from the rate of increase in limb circumference during venous occlusion using an electronic calibration signal and expressed in $\mathrm{ml} / 100 \mathrm{ml} / \mathrm{min}$. Limb vascular resistance was calculated from the ratios of mean blood pressure and forearm and calf blood flows. The results are expressed in units of dyne.s. $\mathrm{cm}^{-5} \times 10^{3}$.

\section{CARDIAC OUTPUT}

Cardiac output was measured by Doppler interrogation of ascending aortic blood flow using a $2.0 \mathrm{MHz}$ continuous wave transducer positioned in the suprasternal notch. The spectral Doppler display was recorded on to light sensitive silver paper at $100 \mathrm{~mm} / \mathrm{s}$ by use of a Biosound ND-256-8 echo Doppler machine. The flow velocity integral was determined for at least three cardiac cycles on a digitising tablet (Terminal Display Systems, 

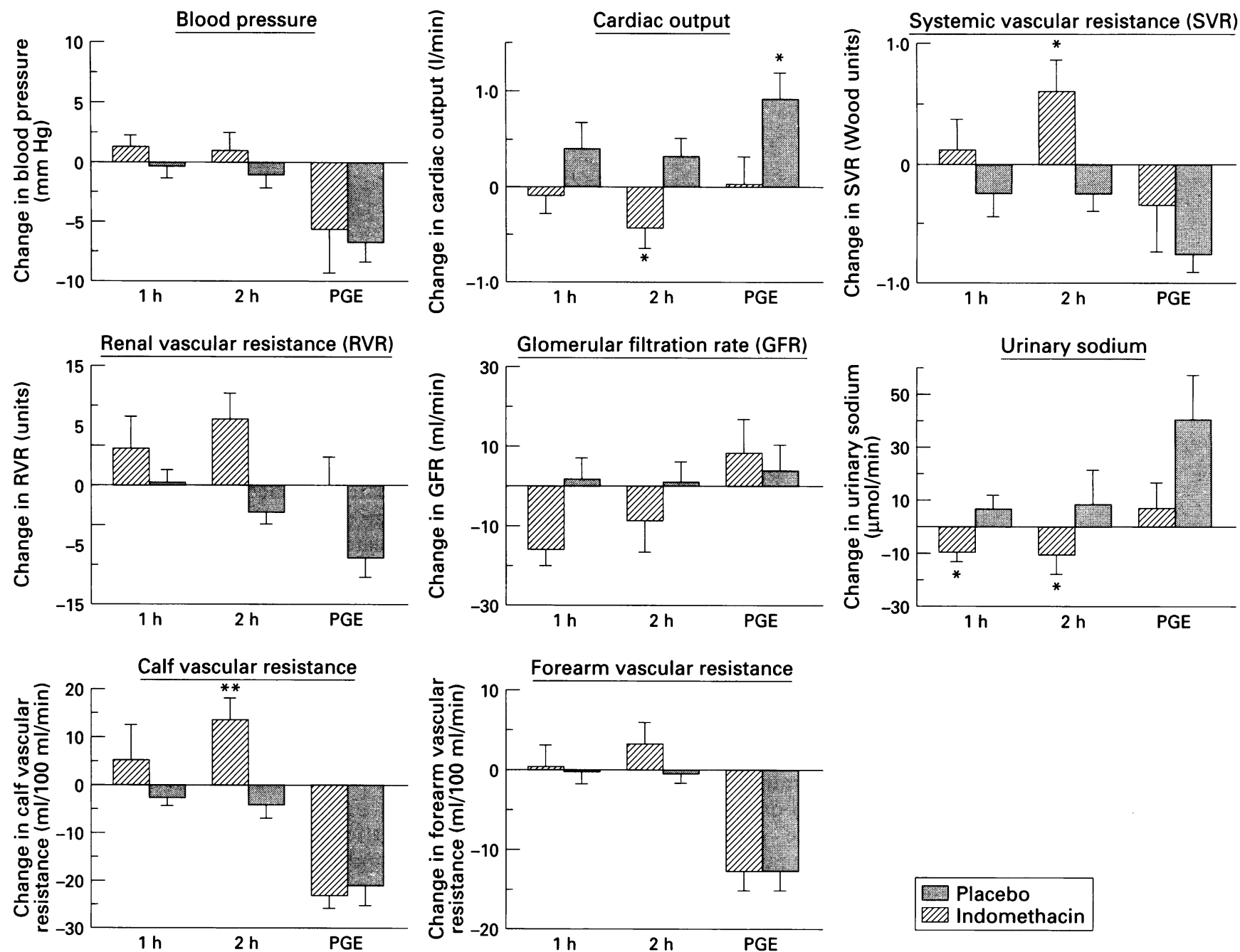

Figure 1 Changes in haemodynamic and renal function at 1 and $2 \mathrm{~h}$ after oral indomethacin 50 mg or placebo and during subsequent intravenous infusion of prostaglandin $E_{2}(P G E)$. Values are mean changes (SEM), ${ }^{\star} P<0.05 ; \star \star P<0.01$.

Blackburn) connected to a personal computer (Archimedes 420/1; Acorn Computers, UK). Stroke volume was calculated using the aortic diameter measured by $M$ mode echocardiography and cardiac output as the product of stroke volume and heart rate.

The studies were performed with the patients resting semisupine in bed in a quiet clinical research room where the temperature was maintained between 20 and $24^{\circ} \mathrm{C}$. Patients were asked to take a light breakfast at least $2 \mathrm{~h}$ before the study period and to refrain from taking any medication on the day of the studies. A 5\% dextrose solution was infused continuously at a rate of $200 \mathrm{ml} / \mathrm{h}$ to encourage adequate urine volumes for clearance studies. Oral fluid intake in the form of water or non-caffeinated beverages was allowed ad libitum.

A loading dose of $p$-aminohippurate (10 $\mathrm{mg} / \mathrm{kg}$ ) was given at the beginning of the studies followed by continuous intravenous infusion at $10 \mathrm{mg} / \mathrm{min}$. Patients were asked to void all urine after a $40 \mathrm{~min}$ equilibration period and a timed $2 \mathrm{~h}$ baseline urine collection was started. During this time pulse rate and blood pressure were measured and baseline cardiac output and forearm and calf blood flow determined. Blood samples were taken from a forearm venous cannula for subsequent measurement of the concentration of plasma prostaglandin $\mathrm{E}_{2}$ and haematocrit. Urine was voided at the end of the baseline period and the volume measured by weighing. Samples of urine and blood were collected for measurement of creatinine and $p$-aminohippurate clearances.

Two studies were conducted. Patients in study A were randomised to receive oral indomethacin $50 \mathrm{mg}$ or placebo at the end of the baseline period. All measurements were then repeated at 60 and $120 \mathrm{~min}$. Further measurements were taken after a $60 \mathrm{~min}$ infusion of prostaglandin $E_{2}$. Patients in study $B$ were once again assigned randomly to receive indomethacin $50 \mathrm{mg}$ or placebo $30 \mathrm{~min}$ before an oral dose of captopril $25 \mathrm{mg}$. Measurements were repeated at 60 and 120 min after captopril administration. For each study indomethacin (non-proprietary) was placed in a gelatin capsule and packed around with dextrose powder. Identical capsules containing only dextrose were used as placebo. Randomisation was in blocks of four.

Blood samples for assay of prostaglandin $E_{2}$ were collected in to chilled heparinised tubes containing $0.5 \mathrm{ml}$ of $1 \%$ indomethacin in solution and centrifuged immediately. Concentrations of plasma prostaglandin $\mathrm{E}_{2}$ were measured by radioimmunoassay using 
Figure 2 Changes in the concentration of plasma prostaglandin $E_{2}$ (PGE) after oral indomethacin 50 mg or placebo and during subsequent infusion of PGE with time. There was no significant difference between indomethacin and placebo treatment groups. Values are mean (SEM). $B L$, baseline.

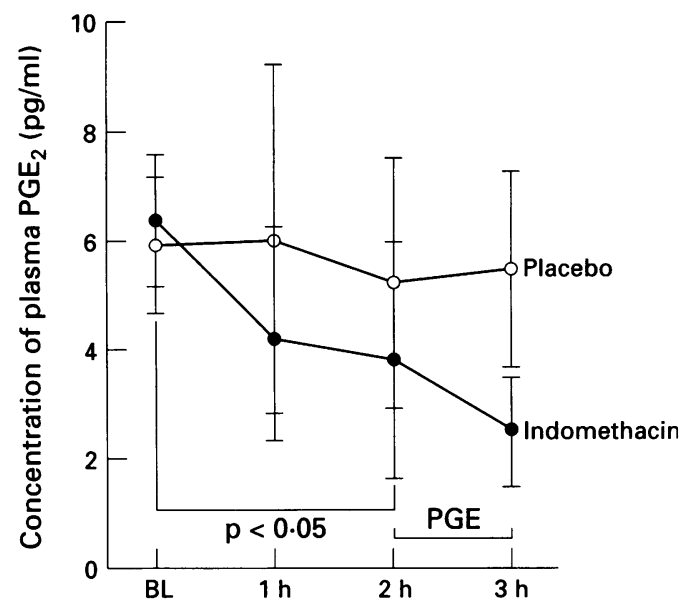

materials from Amersham International (UK) (assay system RPA 530). The plasma was acidified using acetic acid and after centrifugation was extracted on $\mathrm{C} 18$ columns. Prostaglandin $\mathrm{E}_{2}$ was converted to the methyl oximate derivative using methoxyamine hydrochloride after drying and reconstitution with phosphate buffered gelatin saline solution. The concentration of prostaglandin $\mathrm{E}_{2}$ methyl oximate was assayed by radioimmunoassay using prostaglandin $\mathrm{E}_{2}$ labelled with iodine- 125 as a competitive agonist for a specific antibody. The claimed antiserum cross reactivity for this assay is $5 \%$ with prostaglandin $E_{1}$. The coefficient of variation for the assay calculated using paired duplicates was $6 \cdot 4 \%$.

\section{STATISTICAL METHODS}

Patients were randomised in blocks of four so that equal numbers were allocated to treatment and placebo. Because of the wide interpatient variation in the baseline values of all parameters we have not examined absolute values but have compared the changes after administration of indomethacin with those after placebo between groups using an unpaired $t$ test. Values are means (SEM) unless otherwise specified.

\section{Results}

EFFECTS OF INDOMETHACIN

Figure 1 shows the changes in central and peripheral haemodynamics and renal function after administration of indomethacin and during the subsequent prostaglandin $\mathrm{E}_{2}$ infusion. Indomethacin had no significant effect on mean blood pressure but there was a reduction in cardiac output at $2 \mathrm{~h}$ after administration of indomethacin of $-0.42(0.2) \mathrm{l} / \mathrm{min}$ which differed significantly from the mean increase after placebo of $0.33(0.2) 1 / \mathrm{min}(\mathrm{P}<$ $0.05)$. The change in systemic vascular resistance at $2 \mathrm{~h}$ after indomethacin was an increase of $6.1(2.5)$ Wood units compared with a mean decrease of $-2 \cdot 7(1 \cdot 6)$ Wood units after administration of placebo $(\mathrm{P}<$ $0.05)$. Renal blood flow at $2 \mathrm{~h}$ after indomethacin decreased $(-79$ (31) $\mathrm{ml} / \mathrm{min})$, while there was an increase in the placebo group $(52(23) \mathrm{ml} / \mathrm{min})(P<0.01)$. Renal vascular resistance increased with indomethacin $(8.1(3.2)$ units $)$ in contrast to placebo $(-3.6(1.4)$ units $)(P<0.02)$. The changes in glomerular filtration rate at 1 and $2 \mathrm{~h}$ after indomethacin were $-15(4) \mathrm{ml} / \mathrm{min}$ and $-9(7) \mathrm{ml} / \mathrm{min}$ compared with 2 (4) $\mathrm{ml} / \mathrm{min}$ and 1 (5) $\mathrm{ml} / \mathrm{min}$ respectively in the placebo group ( $P<0.02$ at $1 \mathrm{~h}$ and 0.19 at $2 \mathrm{~h}$ ). Filtration fraction was not significantly affected by indomethacin; the mean change in filtration fraction in the indomethacin group was $4(6) \%$ at $2 \mathrm{~h}$ compared with -5 (3)\% in the placebo group $(P=0 \cdot 2)$. There was a small decrease in urinary sodium excretion in the indomethacin group $(-9$ (4) $\mu \mathrm{mol} / \mathrm{min}$ and $-10(7) \mu \mathrm{mol} / \mathrm{min}$ at 1 and $2 \mathrm{~h}$ ) in contrast to the small increases in the placebo group (8 (5) $\mu \mathrm{mol} / \mathrm{min}$ and 9 (12) $\mu \mathrm{mol} / \mathrm{min}$ ) $(\mathrm{P}<0.05$ at $1 \mathrm{~h}$ and 0.2 at $2 \mathrm{~h}$.

The changes in forearm blood flow and vascular resistance after indomethacin were not significantly different from those of placebo. At $2 \mathrm{~h}$ after indomethacin, however, the mean change in calf blood flow was $-0.2(0.05) \mathrm{ml} / \mathrm{min} / 100 \mathrm{ml}$ compared with $0.07(0.04) \mathrm{ml} / \mathrm{min} / 100 \mathrm{ml}$ after placebo $(P<0.01)$. The change in calf vascular resistance after indomethacin was also significantly different from placebo; the mean change in vascular resistance at $2 \mathrm{~h}$ after indomethacin was 13 (5) units compared with -4 (3) units after placebo $(P<0.01)$.

Infusion of prostaglandin $\mathrm{E}_{2}$ increased cardiac output in the indomethacin group to near baseline values with a mean change of only $0.03(0.3) \mathrm{l} / \mathrm{min}$; in contrast, there was a significant increase over baseline values in the placebo group of $0.9(0.3) \mathrm{l} / \mathrm{min}(P<0.05)$. Renal vascular resistance in the placebo group was significantly reduced in comparison with baseline values by infusion of prostaglandin $E_{2}$ but returned to near baseline values after administration of indomethacin. Improvements in limb vascular resistance with prostaglandin $\mathrm{E}_{2}$ were evident but not significantly different between the two groups.

Concentration of plasma prostaglandin $E_{2}$

The mean baseline concentration of prostaglandin $\mathrm{E}_{2}$ in the patients was $4.9(0.50)$ $\mathrm{pg} / \mathrm{ml}$, a value not significantly different from that of ten normal control subjects (not age matched) who had a mean concentration of $4.40(1 \cdot 70) \mathrm{pg} / \mathrm{ml}$. Figure 2 shows the changes in mean concentration of plasma prosta-glandin $\mathrm{E}_{2}$ after administration of indomethacin or placebo. There was no significant change in the concentration of plasma prostaglandin $\mathrm{E}_{2}$ compared with that of placebo but, in comparison with the baseline value a significant decrease occurred in the indomethacin group. There was no increase in the concentration of venous prostaglandin $\mathrm{E}_{2}$ during exogenous infusion of the agent.

EFFECTS OF PRETREATMENT WITH INDOMETHACIN ON THE ACUTE RESPONSES TO CAPTOPRIL

Figure 3 shows the effects of pretreatment with indomethacin on the acute responses to 

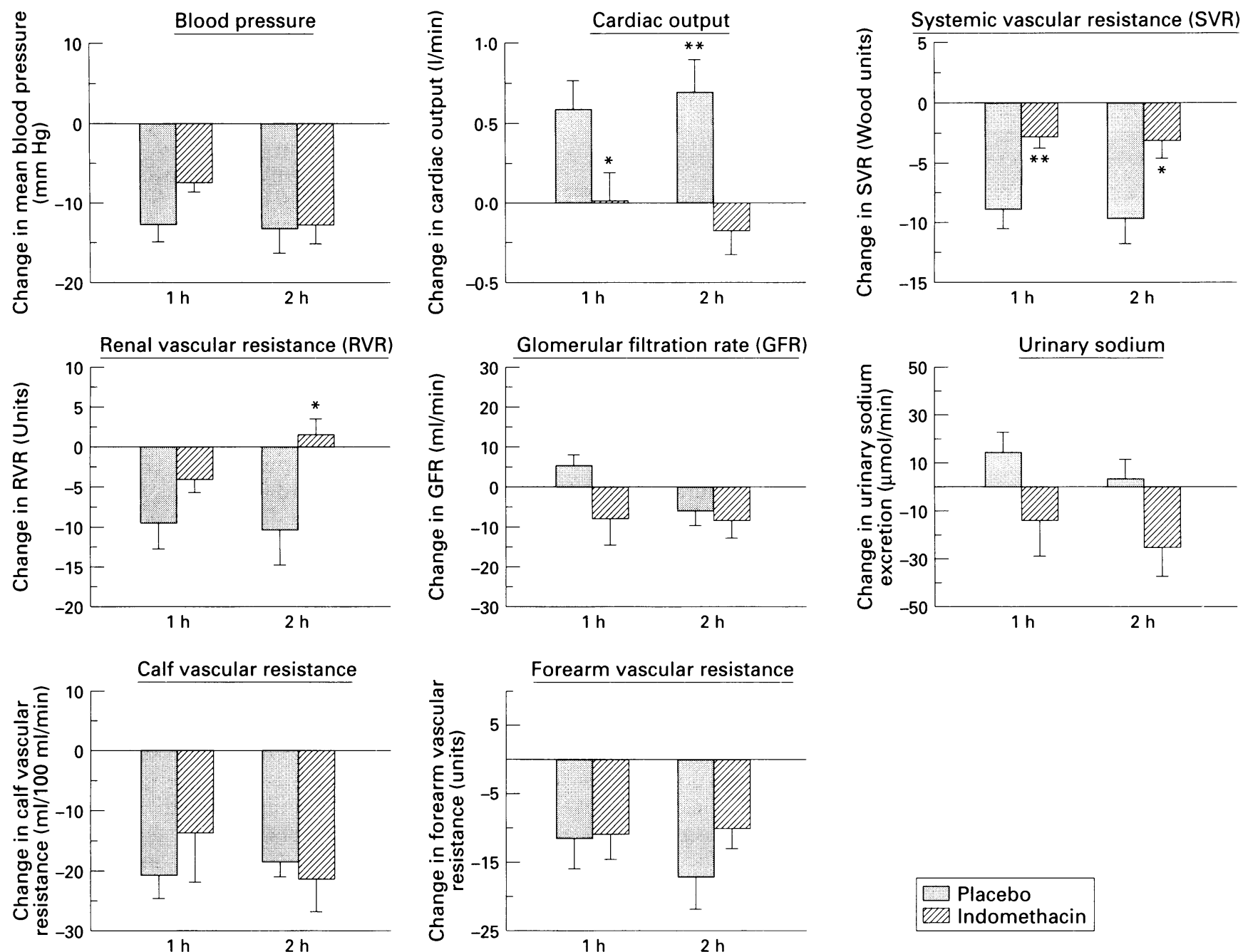

Figure 4 Changes in the concentration of plasma prostaglandin $E_{2}(P G E)$ after oral captopril $25 \mathrm{mg}$ with oral indomethacin $50 \mathrm{mg}(\mathrm{O})$ or placebo (-) pretreatment with time. There was no significant difference between indomethacin and placebo pretreatment groups. Values are mean (SEM). BL, baseline.

captopril. The increase in cardiac output with captopril was significantly attenuated by indomethacin pretreatment. The change in cardiac output with indomethacin pretreatment was $0.02(0.2) \mathrm{l} / \mathrm{min}$ at $1 \mathrm{~h}$ and -0.15 $(0 \cdot 15) \mathrm{l} / \mathrm{min}$ at $2 \mathrm{~h}$ compared with $0.60(0.17)$ $1 / \mathrm{min}$ and $0.70(0.2) 1 / \mathrm{min}$ with placebo pretreatment $(P<0.05$ at $1 \mathrm{~h}$ and $<0.01$ at $2 \mathrm{~h}$. There was no significant difference between the indo-methacin and placebo groups when changes in blood pressure after captopril were examined. The reductions in calculated sys-

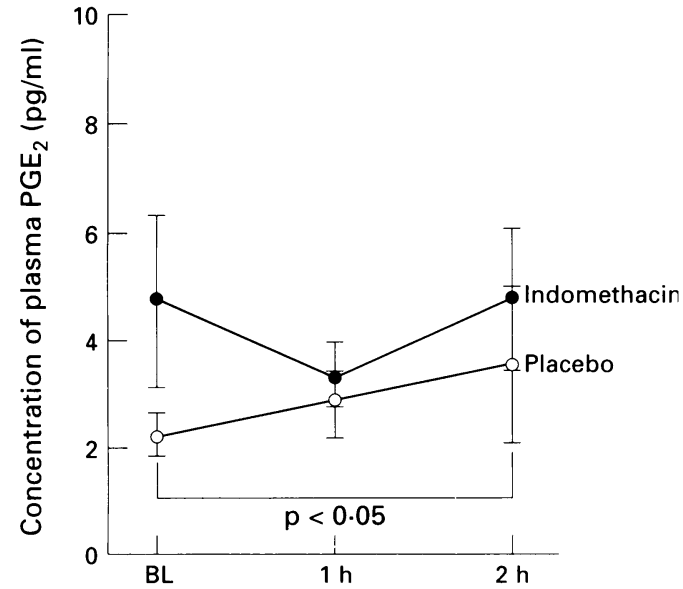

temic vascular resistance were significantly attenuated by indomethacin pretreatment. At $1 \mathrm{~h}$ the mean fall in systemic vascular resistance with placebo pretreatment was -8.9 $(1.5)$ Wood units compared with only $-2 \cdot 7$ $(1 \cdot 1)$ Wood units with indomethacin pretreatment $(\mathrm{P}<0.01)$. At $2 \mathrm{~h}$ the difference was still apparent with a mean decrease in systemic vascular resistance in the placebo group of $-9.6(2.0)$ Wood units and $-3.1(1.5)$ Wood units in the indomethacin group $(\mathrm{P}<$ $0 \cdot 05)$.

The increase in renal blood flow after captopril was significantly reduced by indomethacin pretreatment. At $2 \mathrm{~h}$ the change in renal blood flow after captopril was -74 (41) $\mathrm{ml} / \mathrm{min}$ with indomethacin pretreatment compared with $73(52) \mathrm{ml} / \mathrm{min}$ in the placebo pretreatment group $(P<0.05)$. The change in renal vascular resistance in the indomethacin group at $2 \mathrm{~h}$ was 2 (2) units compared with -10 (5) units in the placebo group $(P<$ $0.05)$. Changes in urinary sodium excretion and glomerular filtration rate were not significantly different in the two groups, although the mean change in urinary sodium excretion at $2 \mathrm{~h}$ after captopril in the indomethacin pretreatment group was -25 (14) $\mu \mathrm{mol} / \mathrm{min}$ compared with $3(8) \mu \mathrm{mol} / \mathrm{min}$ in the placebo pretreatment group $(P=0.09)$. 
Changes in forearm and calf blood flow and vascular resistance after captopril were not significantly affected by indomethacin pretreatment.

Concentration of plasma prostaglandin $E_{2}$ No significant differences in the concentration of plasma prostaglandin $E_{2}$ between the indomethacin and placebo pretreatment groups were detected (fig 4). In comparison with the baseline value, however, there was a small increase in the concentration of prostaglandin $E_{2}$ after captopril in the placebo pretreatment group $(P<0.05$, paired $t$ test).

\section{Discussion}

In this controlled randomised study indomethacin caused adverse effects on cardiac output and systemic vascular resistance in patients with chronic heart failure. In addition, there was an increase in renal vascular resistance, a reduction in glomerular filtration rate and urinary sodium excretion, and an increase in calf vascular resistance. Infusion of prostaglandin $E_{2}$ resulted in restoration to near baseline values of cardiac output, renal blood flow, and urinary sodium excretion. Limb muscle haemodynamics were improved to values greater than the baseline by prostaglandin $\mathrm{E}_{2}$ in indomethacin and placebo groups.

In an uncontrolled study similar adverse effects on cardiac output and systemic vascular resistance were reported in a group of patients with severe heart failure and associated prerenal failure. ${ }^{3}$ Much smaller increases in systemic vascular resistance have also been reported in normal individuals during intravenous infusion of indomethacin. ${ }^{11}$ Taken with the results of this controlled study, such evidence suggests that products of the cyclooxygenase system (the synthesis of which is inhibited by indomethacin) exert a vasodilating effect which may be of importance in states characterised by vasoconstriction such as heart failure. The reversal of the effects of indomethacin on cardiac output and renal haemodynamics by exogenous prostaglandin $E_{2}$ supports the contention that the actions of indomethacin were caused by inhibition of vasodilatory prostaglandin synthesis.

The individual vascular beds in which prostaglandins have a role in maintaining blood flow in heart failure have not been subject to detailed investigation. This study helps to confirm a small body of uncontrolled evidence suggesting that the inhibition of prostaglandin synthesis has adverse effects on renal blood flow in heart failure. ${ }^{5}$ Similar evidence exists for other pathological states in which renal blood flow is reduced such as liver disease. ${ }^{12}$ There are also experimental data showing that indomethacin reduces renal blood flow during acute reduction in cardiac output in dogs. ${ }^{13}$ In contrast, inhibition of prostaglandin synthesis in healthy sodium replete individuals has little or no effect on renal perfusion or function suggesting that normal renal prostaglandin synthesis does not contribute to maintaining renal blood flow. ${ }^{14} 15$

The effects of indomethacin on limb muscle blood flow in heart failure have been little studied. While no significant change in forearm blood flow or vascular resistance occurred after indomethacin, a small but significant decrease in calf blood flow and increase in vascular resistance was evident. Infusion of exogenous prostaglandin $\mathrm{E}_{2}$ resulted in large increases in limb blood flow and reductions in vascular resistance. In healthy human individuals indomethacin seems to have no effect on resting skeletal muscle blood flow. ${ }^{16}$ In experimental animals, however, angiotensin induced vasoconstriction in skeletal muscle is potentiated by indomethacin. ${ }^{17}$ Thus the role of prostaglandins may be to maintain muscle blood flow during conditions of prior vasoconstriction. The reason for the lack of effect of indomethacin on forearm blood flow in heart failure when such an effect was demonstrable in the calf is unclear but may be related to the smaller muscle mass or occasional practical difficulties in obtaining good quality plethysmographic results from the forearm which patients find more difficulty in holding stationary than the calf. There may also be differences in the control mechanisms in the two vascular beds. Differences between the forearm and calf vascular responses to changes in posture, contralateral arm exercise, and mental stress have been described. ${ }^{18} 19$ These are thought to be the result of differences in innervation but it is possible that there may also be differences in local control mechanisms.

The results of study $B$ indicate that some of the beneficial haemodynamic effects of captopril in heart failure may be mediated by an increase in vasodilatory prostaglandin synthesis. Pretreatment with indomethacin significantly attenuated the increase in cardiac output and the reduction in systemic vascular resistance after captopril. A similar study examining the effect of aspirin on the haemodynamic changes after enalapril in heart failure demonstrated that aspirin significantly attenuated the decrease in pulmonary and systemic vascular resistance and left ventricular filling pressure seen when enalapril was given with inactive placebo. ${ }^{20}$

Indomethacin severely attenuated the renal haemodynamic response to captopril. The increase in renal blood flow as a result of a reduction in renal vascular resistance in the placebo pretreatment group was in contrast to the mean reduction in renal blood flow with a slight increase in vascular resistance seen after indomethacin pretreatment. These results suggest that prostaglandins may be important in mediating the acute increase in renal blood flow caused by angiotensin converting enzyme inhibitors in chronic heart failure. An increase in renal blood flow is believed to be an important part of the action of these agents in heart failure. ${ }^{21}{ }^{22}$ The increase in renal blood flow is larger than the increase in cardiac output; almost half of the increase in cardiac output may be distributed to the kidney. ${ }^{21}$ This "selective" renal vasodilatation is a feature of 
angiotensin converting enzyme inhibitors not seen with most other vasodilators and may be related to an increase in renal vascular prostaglandin synthesis. In some respects, however, the finding is paradoxical as angiotensin II stimulates prostaglandin synthesis. ${ }^{23}$

No significant effect of indomethacin pretreatment on captopril mediated changes in forearm and calf blood flow or vascular resistance was demonstrated in this study. This is in contrast to the work of Nishimura et $a l^{4}$ who examined the effect of captopril on plasma prostaglandin levels and forearm haemodynamic function in 14 patients with severe heart failure. Captopril caused a significant acute increase in forearm blood flow which was associated with increases in plasma prostaglandin $E_{2}$ and prostaglandin $I_{2}$ metabolites. Pretreatment with indomethacin eliminated the increase in plasma prostaglandins (leaving the effects on the renin angiotensin system unchanged) and significantly blunted the increase in forearm blood flow. The study was not blinded or controlled and no measurements were made of cardiac output so that it cannot be certain whether the effects of indomethacin were "central" or peripheral. The results of the work presented here lend no support to the suggestion that vasodilatory prostaglandins have a role in increasing muscle blood flow after angiotensin converting enzyme inhibitor treatment in heart failure.

Some methodological problems may have influenced the results obtained in this study. We have measured several variables in a relatively small number of patients raising concern about the possible detection of false positive results and about the power of the study to detect biologically meaningful differences. In a study of this size the two sample unpaired $t$ test assuming equal variances has a power of approximately $90 \%$ to detect a difference in group means of a magnitude of one standard deviation of the variable and approximately $60 \%$ to detect a difference of half a standard deviation. Most of the effects of interest in this study were nearer to the former situation. Although false positive results cannot be excluded the effects appear to be consistent and to occur in the directions that their biological correlation would suggest.

The use of indomethacin as a pharmacological probe to evaluate the effects of inhibition of prostaglandin synthesis assumes that prostaglandins are the only vasoactive system affected by this drug and that indomethacin has no direct vascular actions. Apart from inhibition of cyclo-oxygenase, other effects of indomethacin include inhibition of superoxide generation, interference with leukocyte migration, and in vitro inhibition of the enzyme phosphodiesterase, ${ }^{25}$ although the blood concentrations of indomethacin reached in man are not known to affect other enzyme systems. An investigation of the effects of other structurally dissimilar non-steroidal agents would be helpful. Perhaps surprisingly, no reduction in the concentration of circulating prostaglandin $\mathrm{E}_{2}$ after administration of indomethacin compared with that after placebo was demonstrated in this study. Several factors may have influenced the measurement of plasma prostaglandin $\mathrm{E}_{2}$ concentrations. Although blood was taken via indwelling cannulae and collected into tubes containing indomethacin, release of prostaglandins by the vessel wall and cellular components of blood during sample collection may have increased the concentration of the plasma sample tending to obscure decreases due to indomethacin. In addition, all of the available radioimmunoassays, including the one employed in this work, operate close to their lower limits of detection when measuring concentrations of about $5 \mathrm{pg} / \mathrm{ml}$. Perhaps most importantly, it must be remembered that prostaglandins are locally acting substances and thus it is the local tissue concentrations which cause the physiological effects; such concentrations may bear little relation to circulating concentrations. Similarly, the failure of plasma prostaglandin $\mathrm{E}_{2}$ concentrations to increase with intravenous infusion may be a function of the rapid degradation of these compounds during their passage through the various vascular beds.

Clearance techniques to determine renal blood flow and glomerular filtration rate allowed serial measurements but they are critically dependent on accurate urine volumes, we could not justify the use of urinary catheters and therefore had to assume that voiding was complete. In addition, the use of endogenous creatinine clearance to measure glomerular filtration rates is inaccurate at low levels of glomerular filtration ${ }^{26}$; inulin or radiolabelled chelate clearance techniques are more accurate. When determining consecutive changes in the same patient, however, the error in creatinine clearance should be consistent and the method avoids repeated exposure to ionising radiation and the generally acknowledged difficulties of inulin assay.

Despite these problems this study provides controlled evidence that prostaglandin synthesis has a role in the regulation of renal and probably also limb muscle blood flow in heart failure. In addition, interactions of captopril with the kinin prostaglandin system may account for some of the well known beneficial effects of this agent in heart failure. This study also confirms the adverse haemodynamic effects of non-steroidal anti-inflammatory agents in heart failure and provides further evidence that the benefits of angiotensin converting enzyme inhibitors in heart failure may be attenuated by such agents. The implications of this interaction in the clinical setting are obvious but may not be generally recognised. In the SOLVD (Studies on Left Ventricular Dysfunction) prevention study, enalapril had a significantly lesser effect on mortality in patients receiving antiplatelet agents than on those not receiving such treatment. ${ }^{27}$ There is increasing evidence to suggest that not only should non-steroidal agents be avoided in heart failure but that aspirin should be discontinued in patients starting angiotensin converting enzyme inhibitor treatment for heart failure. 
JNT was supported by a British Heart Foundation Junior Research Fellowship. Statistical advice was supplied by Dr P Davies, School of Mathematics and Statistics, University of Birmingham.

1 Levenson DJ, Simmons CE, Brenner BM. Arachidonic acid metabolism, prostaglandins and the kidney. $A m \mathcal{F}$ Med 1982;72:354-74.

2 Dusting GJ, Moncada S, Vane JR. Prostaglandins, their intermediates and precursors: cardiovascular actions and regulatory roles in normal and abnormal circulatory regulatory roles in normal and abnormal circ

systems. Prog Cardiovasc Dis 1979;21:405-30.
3 Dzau VJ, Packer M, Lilly LS, Swartz SL, Hollenberg NK, Williams GH. Prostaglandins in severe congestive heart Williams GH. Prostaglandins in severe
failure. $N$ Engl f Med 1984;210:347-52.

4 Dzau VJ. Vascular and renal prostaglandins as counterregulatory systems in heart failure. Eur Heart $\mathcal{f} 1988$; 9(suppl H): 15-9.

5 Walshe JJ, Venuto RC. Acute oliguric renal failure induced by indomethacin: possible mechanism. Ann Intern Med 1979;91:47-9.

6 Yang HY, Erdos EG, Levin Y. A dipeptidyl carboxypeptidase that converts angiotensin I and inactivate bradykinin. Biochim Biophys Acta 1970;214:374-6.

7 Dzau VJ, Swartz SL. Dissociation of the prostaglandin and renin angiotensin systems during captopril therapy for chronic congestive heart failure secondary to coronary artery disease. Am $\mathcal{F}$ Cardiol 1987;60:1 101-5.

8 Moore TJ, Crantz FR, Holenberg NK, Koletsky RJ, Moore TJ, Crantz FR, Holenberg NK, Koletsky RJ,
Leboff MS, Swartz SL, et al. Contribution of prostaLeboff MS, Swartz SL, et al. Contribution of prosta-
glandins to the antihypertensive actions of captopril in glandins to the antihypertensive actions of captopril
essential hypertension. Hypertension 1981;3:168-73.

9 Swartz SL, Williams GH. Angiotensin converting enzyme inhibitors and prostaglandins. Am $\mathcal{f}$ Cardiol 1982;49: 1405-9.

10 Chasis H, Redish J, Goldring W, Ranges HA, Smith HW. Use of sodium p-aminohippurate for functional evaluation of human kidney. $\mathcal{F}$ Clin Invest 1945;24:583-8.

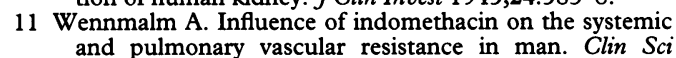
1978;54:141-5.

12 Boyer TD, Zia P, Reynolds TB. Effect of indomethacin and prostaglandin $\mathrm{Al}$ on renal function and plasma renin activity in alcoholic liver disease. Gastroenterology renin activity in

13 Oliver JA, Sciacca RR, Pinto J, Cannon PJ. Participation of the prostaglandins in the control of renal blood flow
during acute reduction of cardiac output in the dog. $F$ Clin Invest 1981;67:229-37.
14 Gullner HG, Gill JR, Bartter FC, Dusing R. The role of the prostaglandin system in the regulation of renal function in normal women. $A m \mathcal{F}$ Med 1980;69:718-24.

15 Donker AJM, Arisz L, Brentjens JR. The effect of indomethacin on kidney function and plasma renin activity in man. Nephron 1976;17:288-96.

16 Kilbom A, Wennmalm A. Endogenous prostaglandins as local regulators of blood flow in man: effect of indomethacin on reactive and functional hyperaemia. $\mathcal{f}$ Physiol 1976;257:109-21.

17 Messina EJ, Weiner R, Kaley G. Inhibition of bradykinin vasodilation and potentiation of norepinephrine and angiotensin vasoconstriction by inhibitors of prostaglandin synthesis in skeletal muscle of the rat. Circ Res glandin synthesis

18 Duprez D, Essandoh LK, Shepherd JT. Postural cardiovascular reflexes involve forearm but not calf resistance vascular reflexes involve forearm but not calf
vessels. $\mathcal{F}$ Hypertens 1987;5(suppl 5):S331-2.

19 Rusch NI, Shepherd JT, Clinton Webb R, Vanhoutte PM. Different behaviour of the resistance vessels of the human calf and forearm during contralateral isometric exercise, mental stress, and abnormal respiratory movements. Circ Res 1981;48(suppl I): 118-30.

20 Hall D, Zeitler H, Rudolph W. Counteraction of the vasodilator effects of enalapril by aspirin in severe hear failure. $\mathcal{A} \mathrm{Am}$ Coll Cardiol 1992;20:1549-55.

21 Creager MA, Halperin JL, Bernard DB, Faxon DP, Melidossian CD, Gavras $\mathrm{H}$, et al. Acute regional circulatory and renal hemodynamic effects of converting enzyme inhibition in patients with congestive heart failure. Circulation 1981;64:483-9.

22 Cleland JGF, Dargie HJ, Ball SG, Gillen G, Hodsman GP, Morton JJ, et al. Effects of enalapril in heart failure: GP, Morton JJ, et al. Effects of enalapril in heart failure: a double blind study of the effects on exercise performance, renal function, horm

23 Lote CJ, Haylor J. Eicosanoids in renal function. Prostaglandins, Leukotrienes and Essential Fatty Acids: Reviews 1989;36:203-17.

24 Nishimura H, Kubo S, Ueyama M, Kubota J, Kawamura K. Peripheral hemodynamic effects of captopril in patients with congestive heart failure. Am Heart $f$ 1989;117:100-5.

25 Simon LE, Mills JA. Non-steroidal anti-inflammatory drugs. N Engl F Med 1980;302:1179-85.

26 Shemesh O, Golbetz H, Kriss JP, Myers BD. Limitations of creatinine as a filtration marker in glomerulopathic patients. Kidney Int 1985;28:830-8.

27 Pitt PHB. Use of converting enzyme inhibitors in patients with asymptomatic left ventricular dysfunction. $\mathcal{f} \mathrm{Am}$ with asymptomatic left ventric
Coll Cardiol 1993;22:158A-61A. 